\title{
ADAPTATION AND MENTAL RESILIENCE OF CHILDREN, PARENTS, IN GREEK KINDERGARTEN SCHOOLS DURING THE NEW ERA OF PANDEMIC COVID-19. TEACHERS' VIEWS
}

\author{
Paraskevi Foti ${ }^{i}$ \\ Dr., Educational Coordinator, \\ Greek Ministry of Education and \\ Religious Affairs, \\ Scientific Stuff in University of West Attica,
}

Greece

\begin{abstract}
:
The pandemic of Covid-19 has invaded in our lives, with multiple and multidimensional challenges. During the close of school units in Greece at March, teachers were initially used types of distance education, while with the opening of the schools during June they had to face issues, such as the separation of classes, the observance of distances, the use of medical mask, experiencing a new, unprecedented situation. In this paper, reference will be made to key issues of adaptation and mental resilience of children and adults. Then a research carried out will be presented in schools of Primary Education of Athens during the period of June and reopening of school units and teacher's views on the adaptation of children and parents.
\end{abstract}

Keywords: mental resilience, crisis, adaptation, kindergarten, teacher's views

\section{Introduction}

Modern Greek and world society is experiencing a global crisis called Covid-19. In this crisis, the interconnected family-society school functions as a communicating vessel that transports all these problems from the macro level of society to the micro level of the family and finally into the classroom.

In the present work we refer to the concept of "Mental Resilience" clarifying terms such as "crisis situation" and "mental resilience" and then the presentation of results regarding research conducted in primary schools in Athens. This research involved kindergarten teachers who expressed their views on issues of adaptation of children, parents, and teachers to the new era of the Covid-19 pandemic.

The development of social and emotional skills that contribute to the positive adjustment and mental well-being of the individual are a different approach to the field

i Correspondence: email vivifoti@gmail.com 
of school psychology. A key role in this approach of recent studies has the concept of mental resilience, which refers to the process of positive adjustment of individuals despite whatever difficult situations they face (Hatzichristou, 2011b). But what is mental resilience and why do we refer to it?

\section{Mental Resilience}

One of the definitions of "Mental Resilience" is one that refers to an individual's ability to recover, to endure adversity, and to rebuild himself. (Wolin 1993). The term "mental resilience" refers to a dynamic process in which the individual exhibits positive adjustment or the ability to maintain or regain mental health in the face of challenges or adverse conditions (Luthar \& Ciccheti, 2000. Miller \& Daniel, 2007).

Durability is not a one-dimensional, dichotomous trait that an individual has or does not have. It has been reported that a resilient individual should experience positive outcomes in multiple aspects of life over a period (Cicchetti \& Rogosch, 1997). In addition, resilience involves the existence of many skills, to varying degrees, that help an individual cope with situations (Alvord \& Grados, 2005).

Resistant individuals can withstand, overcome, or recover from a serious threat (Masten, 2001). Although many definitions of mental resilience have been formulated, they all contain two elements in common: a) exposure to risk and b) the corresponding factors that contribute to the promotion of positive outcomes and the reduction of negative ones (Fergus \& Zimmerman, 2005).

In fact, Garmezzy and Masten (1991) define mental resilience as the process, ability, and result of a successful adjustment despite the threatening, challenging, and adverse situations that individuals are called upon to face.

The family and parents, when they create a positive climate of acceptance, recognition and security and a supportive environment, where discipline and autonomy are harmoniously balanced, contribute to the formation of an integrated personality (Gutman, Brown, Akerman, \& Obelenskaya, 2010). Then as the child enters school and their social world expands, the teacher's attitude and behavior, as well as the expectations and beliefs he or she has about his or her students, can shape the child's own self-image. (Bruzos, A. 2004).

The interconnected school-family-society link acting as communicating vessels transports all these problems from the wider community environment into the classroom, an issue which we experienced and are experiencing during the pandemic period.

But what do we mean by "crisis situation"?

\section{Crisis}

A crisis could be defined as a temporary situation that causes intense stress and disorganization and is characterized by the inability of the individual to control and manage this event. It can often be experienced by the child as a "trauma", meaning that 
the child's mental function is severely disturbed for a long time (longer than 6 months) (Hadjichristou 2011b).

Developmental crises are one of the two general categories and relate to events related to the transition of the individual from one stage of the life cycle to another. Indicative examples are the beginning of school life, the transition from kindergarten to kindergarten (Foti, P. 2000). Occasional crises are unexpected and affect not only the individual, but also the community to which he belongs, such as accidents, losses (death of loved ones), illness, divorce, school bullying, financial crisis, natural disasters (earthquakes, floods, etc.). a.), war, refugees, terrorist acts, but also pandemics such as Covid-19 (Koliopanou 2011)

Therefore, we are talking about a state of crisis, which is experienced by children, parents and their families, teachers, and society in general and the whole planet. In the context of this global crisis, we tried to investigate the reactions of children and teachers by conducting a survey in the schools of the Primary Education of Athens and specifically in kindergarten teachers, immediately after the opening of the schools in June 2020 and according to the new situation .

\section{Material and Methods}

The choice between quantitative and qualitative research is based on the form of the data. In the present research approach, quantitative research will be applied for more efficient collection of quantitative data and their analysis with statistical tools and methods. Quantitative data have a numerical or analog form and can be presented in diagrams and figures, facilitating the interpretation of research results (Dimitropoulos, 2001).

However, this quantification of data does not prevent, on the other hand, the qualitative summary of the results (Dimitropoulos, 2001). At the same time, in quantitative research it is possible: a) the production of numerical data that can lead to a wider investigation of the subject (Cohen \& Manion, 1994), b) the control of one or more hypotheses, c) the interpretation of cause and effect, and d) the forecasts / estimates. Another positive element of quantitative research is that the researcher is unknown, and the participants are anonymous, so they answer the questions more honestly.

Although quantitative research makes it possible to approach a large part of the sample by highlighting the general trends of the population, the present research effort is a pilot study to highlight the importance of the phenomenon of adaptation in the new era of Covid-19

\section{Research tool}

As mentioned, a quantitative research was conducted. The research material comes from the completion of an electronic questionnaire divided into three parts. The first part concerned demographic data of the respondents and the second part the data recording of school units. In the third part of the questionnaire were recorded the teachers views 
regarding the adaptation of children, parents and themselves to the new Covid-19 era and suggestions for good transition practices. The electronic questionnaire was completed by 102 public kindergartens of the Primary Education of Athens and the research was carried out in the period 10 June - 30 June 2020.

The questionnaire was created on Google's online form at https://docs.google.com/forms/d/1gsVMmt CWz2vtGBcqW04DtJZMyK6IgFeP54epVZP $\underline{4 q Y / e d i t}$

The questionnaire as a research tool is a standard means of obtaining information. In this research, it was an indirect means of communication between the researcher and the respondents. As a tool it has several positive elements which include saving time, low cost to negligible (in the case of the electronic questionnaire), the simplicity of the process that does not tire and the reliability of the results from the collection of the representative sample (Lagoumintzis, Vlachopoulos , Koutsogiannis, 2015).

\section{Reliability and validity of research process and measurements}

Two of the necessary characteristics that a measuring tool should have are reliability and validity (Pappas, 2002). Reliability refers to the stability that the research tool displays in successive measurements. A measuring tool is considered reliable when in repeated measurements, in the same sample and at different times, it consistently displays the same results, provided that no significant change has occurred between the measurements (Ch. Ouzouni \& K. Nakakis, 2011). On the other hand, validity shows whether the research tool and the measurements it gives us correctly measure what it is intended to measure (Paraskevopoulos, 1999).

To ensure the reliability of the questionnaire, the following steps were followed: 1 ) its completion was voluntary, 2) it was sent electronically via the google docs form, and 3) all stages of a survey were followed. At the same time, each question of the questionnaire was evaluated for its suitability in terms of: 1) its content, 2) its verbal wording, 3) its order in the questionnaire, 4) its type (Paraskevopoulos, 1999). Finally, the closed-ended questions were given a wide range of suggested answers using a five-point Likert scale, and open-ended questions were also asked to increase validity.

\section{Results and Discussion}

In total the electronic questionnaire consisted of 22 questions where the First Part concerned demographic data, such as gender of respondents, age and years of service.

Regarding the gender of the respondents, $91.7 \%$ were women and $8.3 \%$ men (Figure 1).

Regarding the age, 50\% answered that they are from 50-60 years old, 31.3\% aged $40-50$ years old, $14.6 \% 30-40$ years old and $4.2 \& 20-30 \%$ (Figure 2 ).

Regarding the teaching experience, $41.7 \%$ answered from $19-24$ years, $25 \%$ from 25 years and over, $16.7 \%$ from 13-18 years and $4.2 \%$ from 1 to 4 years (Figure 3 ). 
The second part of the questionnaire concerned the data of the school unit. The percentage of children who came to school after the first closure due to Covid-19 and in relation to the total school capacity, $52.1 \%$ of the teachers answered that $70-80 \%$ of total school capacity, $31.3 \%$ answered that $50-70 \%$ of the students came, $10.4 \%$ answered 90 $100 \%$ of total school capacity came, $4.2 \%$ answered $30-50 \%$ of the students came and $2.1 \%$ answered that 10-30\% of total school capacity came to the school (Figure 4).

Regarding whether the students were aware of the protection measures by Covid19, 43.8\% answered that they knew a lot about the measures, $33.3 \%$ very much, $16.7 \%$ that they knew enough and 6.3\% that they knew a little bit (Figure 5).

To the question if the children knew WHY they should apply the necessary measures for Covid-19, the teachers answered at a rate of $33.3 \%$ a lot and a lot, at a rate of $27.1 \%$ a lot and at a rate of $6.3 \%$ a little (Figure 6 ).

The next question was whether there was a common plan concerning the measures to be followed by the school unit, with $64,6 \%$ of teachers answering too positive, $31.3 \%$ very positive and $4.2 \%$ enough (Figure 7 ).

Regarding the next question and the conditions that existed inside each school unit in order to comply with the measures with the distances and the Covid-19 pandemic and after taking into account that there was an alternation of student classes on a daily basis, the teachers at a rate of 39,6\% answered enough, $22.9 \%$ answered a lot, $16.7 \%$ answered a lot and $12.9 \%$ answered a little (Figure 8).

To the next question about the suitability of the outdoor space of each school unit in order to observe the measures with the distances, the teachers answered at a rate of $43.8 \%$ a lot and $33.3 \%$ a lot respectively, at a rate of $14.6 \%$ a lot, the $6,3 \%$ answered a little and $2.1 \%$ answered that there was no suitability (Figure 9).

Regarding whether the parents were informed about the new safety data due to Covid-19, $43.8 \%$ and $35.4 \%$ of the teachers answered that the parents were very, very informed, $18.8 \%$ of the teachers answered quite informed and $2.1 \%$ answered that the parents were a little informed (Figure 10).

The next question was whether the parents of the students were in the mood to talk and communicate with the teachers $47.9 \%$ and $33.3 \%$ of the teachers answered that they wanted very much, $16.7 \%$ answered that they wanted enough and just $2.1 \%$ responded that few parents were willing to communicate with them (Figure 11).

The open question regarding how anxious the parents were about school and the safety measures for Covid-19 recorded the views of the teachers as they answered the questionnaire.

- They considered the measures we took necessary and adapted to them from the first moment.

- The parents were cooperative.

- In addition to the fear of the virus, they brought the children to school and were informed.

- They were cool. Very good treatment.

- The parents were anxious but cooperative.

- Dissatisfaction, wariness, fear, and insecurity. 
- The reactions of the parents were varied. Some parents resented the rotating program, others adapted, and some saw the risk of sending their children to school.

- The parents needed to contact the teachers. For this reason, in addition to the material we sent to the children, there was always an information note to the parents.

- They were positive and less concerned about their children's daily life at school. They were not at all happy with the non-operation of the all-day school as well as with the division of the group into two subgroups

- They were worried.

- Normal behavior although they would prefer their children to come every day.

- Since some parents signed a responsible statement in both sections of the kindergarten, a group operated daily. The parents followed and respected the instructions.

- At first, they felt fear but then they trusted us....

- Cool behavior. Adaptive and cooperative.

- They did not like the closure of the all-day school.

- Cool, a little embarrassed and a little scared.

- Normal behavior.

- Those who brought their children were very relaxed and gave us courage not to stress as they played freely in the squares as they said. There were parents who hesitated a lot if they would bring them, they were very anxious and, in the end, they did not bring them.

- Forced adjustment.

- They felt confident in the school environment and consequently in the kindergarten teachers, so they brought their children without hesitation.

- The parents before and after the return of the children were very cooperative, some quite scared

- In the beginning there was a "numbness" on the part of the parents when the children entered the kindergarten. Then they came out of the window and observed the changed layout of the classroom, with tables across the space and corners that were restricted. But as the days went by, they became more positive and they also adapted to the new reality of the school "

- Anxious but satisfied because the school opened.

Regarding the question of the response of the children to maintaining the necessary safety distance, the teachers answered in a percentage of $50 \%$ and $25 \%$ that the children kept a lot and a long distance, 20.8\% answered a little and $2.1 \%$ of the teachers answered a lot and not at all (Figure 12).

Regarding the question about the response of children to the frequent use of antiseptic, $47.9 \%$ and $43.8 \%$ of teachers answered very much and $8.3 \%$ answered quite a lot (Figure 13).

The next question concerned the response of children to school safety measures with $47.9 \%$ and $31.3 \%$ of teachers answering a lot and enough $16.7 \%$ answered too much and $4.2 \%$ answered a little (Figure 14 ).

The next question was about the response of the children socially and emotionally to safety measures and in 56.3\% the teachers answered that the children answered quite 
well, in $25 \%$ answered very well, $16.7 \%$ answered a little and $2.1 \%$ answered very well (Figure 15).

The next question was about recording thoughts about how the teachers perceived the children's reactions to the opening of the schools adapted to the new reality based on the Covid-19.

- In general, the distance that the children had to maintain made it difficult for everyone. Some children showed a refusal to go to school, which they expressed either verbally or by crying at the time of arrival.

- They were very timid.

- The children asked to play and interact with their classmates and there was dissatisfaction on their part. They also often felt bored.

- At first they felt sad because they broke up with their friends because of the subgroups but they quickly adapted to the new situation.

- The children found it difficult to accept the new composition of the group with the creation of 2 subgroups, the lack of hugs and tenderness that was part of our daily life.

- They missed half of their friends who were coming the next day.

- They did not like the fact that they had to play face to face and from a distance.

- They do not like to keep their distance from their teachers without hugs, without kisses.

- The children were troubled in the first days but in the following days they seemed to adapt to the new situation. What bothered them the most was the fact that they were not a whole team together.

- They came to the kindergarten with a lot of appetite, they expressed their desire to be with their friends, but they were upset that some of their friends did not come.

- They were somewhat surprised by the new environment with the distances and the "retired" games but generally it came in a very good mood.

- The children in the first days of their return were a little cold and hesitant towards both the teachers and the classmates. Day by day, however, their response was improved, and they had more interaction with each other, talking, laughing, telling their news.

- While outwardly they seemed to adapt, they were nevertheless pressed by the new reality

- It was an unprecedented situation for them as they could not play all together mainly in the classroom and that is why they were looking for a break. Some were upset that they could not be with some of their friends. On the other hand we tried to do things they like and games without contact but while initially they kept it as time went on it was very difficult to keep the distance between them. However, they were glad that they came to school and everything said that they missed him a lot.

- The kids were cautious in the early days, looking for friends who were missing or studying in another department, they were missing the whole thing - the composition of the group. They wanted to play team games, create teamwork, and constantly and eagerly asked when they would return to normalcy in the classroom.

- Most children understood the importance of the necessary measures, although they were upset that they could not play with their friends as before and had to follow rules that took away their spontaneity. 
- They had a hard time at first because they did not have all their friends with them .. it was like adjusting again ...

- Puzzled and surprised by their return to school ... they had become accustomed to the different time they fell asleep ... too late.

- They were happy that our school opened, although a little worried that they did not see all their classmates.

- The kids were sometimes unhappy because they couldn't get close to their friends ... that was a bet we had to win ... then I think they adjusted.

- Anxious, sometimes upset but slowly adjusted, or so it seemed.

Regarding the response of the children to the customized schedule of the kindergarten, $52.1 \%$ of the teachers answered a lot, $27.1 \%$ answered a lot, $16.7 \%$ answered a lot while $2.1 \&$ answered that they were late at the beginning (Figure 16).

In the third part of the questionnaire, the questions were asked to the teachers. So in the next question regarding the effect on the change of reality of teachers due to Covid$1935.4 \%$ of teachers and $33.3 \%$ answered that it changed a lot and the reality $22.9 \%$ answered a lot and $8.3 \%$ answered a little (Figure 17).

In the next question the teachers were asked to record their views:

- I felt bad because of my inability to approach the children in my class and I lost my spontaneity in trying to take the right measures.

- Excessive meticulousness.

- We worked with a few children which on its own was positive and the need arose for the schools to be equipped and adequate in crisis situations

- Different organization, limitation in educational planning.

- It is difficult in our work to keep our distance, we need help with some things.

- Much more work was needed because all the material had to be digitized. This required endless working hours as I had to be at school alone in the morning, with reduced staff, because 1/2 of the staff had leave.

- In lifelong teaching I did not have any difficulty at all but during the period when the schools were suspended the new data and the needs that arose created a lot of stress for me.

- Group change - transformation of the classroom into the new situation - need for training in digital tools for distance learning.

- Shaping our classroom differently, without hugs between us and the children, was a difficult bet. Disinfection everywhere and in our materials was stressful.

- Due to the morning presence of all the teachers, the obligations of the school unit were carried out more efficiently.

- I did a lesson with almost half the kids and I had time to deal more with them

- We worked with small groups of children and it was very important

- They were better because of the small number of children and in work and in constructions and in the care of each child and especially they had the time to talk and communicate with each other. 
- It is not possible to undo through the application of the measures, what the children learned for 6 months: I share the toys, I play with the others. This bothered me the most, as the new instructions abolished the old ones. The committee of scientists for the virus did not consider the special character of the kindergarten.

- The children were as tired of the issue of distance as we were. The only positive thing was the small number of children per department which greatly facilitated our work (I wonder how all this will be implemented from September with the departments of 25 children).

- Emotions were mixed. We needed to change the way we work. It is difficult in kindergarten to talk about cooperation and love and not be able to touch someone, not to play group games. That is where I focus change and difficulty.

- It was a different kindergarten ........ It was difficult, but because it did not last I was able to adapt as much as I can and I think I did it .... Since September I am not sure if I can cope with this strange and compulsive function.

- The nature of our work has changed a lot and we had to make the most of our ingenuity to overcome the difficulties and respond to this situation.

- The end of the age of innocence. This is how we could describe the new situation in the kindergarten.

- The small classes helped us not to panic (because we all went to work scared ... at least for the first few days. Slowly we felt the security and joy of our space and we tried very hard to finish as much as we could ... and it was possible with joy from both us and the children.

- Lack of personal contact with children at a time when schools were closed, search-find-adaptation and sending of educational material but also instructions on how to use the material by parents that is, too many hours on the computer.

- I had to keep my distance and that was very stressful.

- In order for all the children to have the same educational stimuli and since we were working in rotation I needed to repeat the same educational program in both groups. The different arrangement of the class did not make it difficult for me since the children did not exceed 9. The biggest difficulty I faced was the longing for hugs and physical contact from both the children and myself. However, we discovered other ways of communicating and expressing emotions with the help of the power of speech and body expression through theatrical art, but also through painting. As teachers we were faced with the need to apply new ways of teaching in which we did not have the necessary training. This added a lot of stress to our daily lives.

- Very difficult situation but efforts have been made and are being made.

- Things are very different .. with great anxiety in the beginning and now anxiety in how the new reality will flow.

- I felt very limited in educational things .. I feel trapped.

- The truth is that our daily life has changed a lot and in terms of school we had to change the whole philosophy of kindergarten and how we should work with children.

- I have had and still have difficulty managing distances with my children. I want to hug them and I can not. It is very difficult..

- I feel that my freedom has been restricted in kindergarten as well.

- Anxious and troubled. 
Regarding the need for pedagogical material adapted to the data of Covid-19, the teachers answered in a percentage of $39.6 \%$ that it is a very, very big need, in a percentage of $12.9 \%$ answered that it is a very big need and in a percentage of $8.3 \%$ a small (Figure 18).

The last question of the questionnaire concerned the recording of teachers' views and thoughts on the new situation and the new school year:

- The new school year will find our school teachers better prepared, as we have included in our planning the modules that we will work on from September on the "e-me for all platform in case we need to use distance education again.

- In terms of our capabilities, they are more due to the "extraordinary" knowledge that we gained from seminars that we attended and still attend.

- As for the restrictions, they will be related to the possibility of internet connection as well as to the existence or not of computers in the homes of our students.

- We believe and hope that the new school year will not surprise us unpleasantly as it did this year.

- Unfortunately, the possibilities of shaping the space based on the new measures are almost impossible due to the number of children.

- Possibility of improvement in logistical infrastructure

- The new school year will start with the new data and we will be better prepared for the safety of children. Unfortunately, the large number of children enrolled in kindergarten and their division into groups creates a problem in the formation of the class and especially in the implementation of programs and actions.

- The possibilities for expression and interaction I feel are quite limited. It is something new that does not allow us to know if the safety measures can achieve the comprehensive development of our infants. The children who returned to school had worked and become a team. New kids, toddlers, and toddlers may find it more difficult to fit them into a group with different rules.

- Based on the new data, it is predicted to be a difficult year for both us and our young students.

- I am particularly anxious about how the new school year will go... many things need to be done ...

- I am anxious and anxious about how the new school year will start ... The classes of our kindergarten are very small, and the children are too many. What will happen in the new school year ... it is a stress ...

- I'm worried about whether the conditions for a safe school year can be met. Need more classes and fewer students ... how could this be done?

- I'm worried about how the next school year will go. I think the kindergarten will be "schooled" and will lose all this philosophy of sharing, interacting, communicating.

- Will there be all the prerequisites for a safe school year? This is my anxiety.

\section{Conclusion}

COVID-19 has caused widespread disruption to the daily lives of people around the world as well as to education. Everyone, parents, students, teachers were forced to 
incorporate new practices into their daily lives, such as strict personal hygiene, physical distance, strict adoption of rules for mask use, change of daily schedule and separation of children and classes at school and all this in front of so many unknowns that we do not know and that it is difficult for us to know how to proceed.

Concluding the presentation of the results, we understand from the answers of the teachers that the promotion of mental resilience can be the main goal for both children and adults. The crisis we are experiencing could be a challenge to seek a new balance both personally and socially with a focus on cultivating interpersonal relationships at both family and personal level and at school. This different reality and new conditions require mutual support and cooperation between all. Schools can be "mentally resilient communities" that will provide support and guidance to all children and their families and contribute to a healthy return to normalcy.

\section{Conflict of Interest Statement}

The author declares no conflicts of interests.

\section{About the Author}

Paraskevi Foti is a Coordinator of the Primary and Secondary Education at the 3rd Region of Attica (Greek Ministry of Education) and formerly Head of the 4th Kindergarten of Agia Varvara. She has studied piano and higher theory at the National Conservatory of Athens, and she has completed her master's degree (Med) in Intercultural Education and Management of Diversity. She completed her second degree in Psychology at the National and Kapodistrian University of Athens with a specialization in Pedagogical Psychology and her doctoral dissertation (PhD) with the title: "The contribution of ancient Greek language to art and language of Aesop and the added value of ICT Technology" with an Excellent degree. Her first book, entitled "Otherness, Prejudice and Stereotypes in the School Class. Teacher Management Methods "(ed. Grigoris, 2016) was selected as a University chart at Harokopeio University and she has also participated in a collective volume on digital educational scenarios (ed. Grigoris, 2017). Her next book is entitled "Understanding our Language, Ancient and New Greek through Aesop" (ed. Grigoris, 2020), and the next one is entitled "STREAM and Educational Robotics for children aged 3-8years" (ed. Grigoris, 2020) .She has published in many international and national conference proceedings as well as in scientific journals and has a keen interest in Information and Communication Technologies and their contribution to the teaching process. She is an eTwinning and Moodle trainer and she supports open source software. She teaches courses as a Scientific Stuff in the Department of Education and Care of the University of West Attica (since 2011) and in the Postgraduate Program of Pedagogy through Innovative Technologies and Biomedical Sciences of the University of West Attica. Her email is vivifoti@gmail.com and pfoti@uniwa.gr and her website is https://blogs.sch.gr/3syn60-at3/ 


\section{References}

Alvord, M. K., \& Grados, J. J. (2005). Enhancing resilience in children: A proactive approach.Professional Psychology: Research and Practice, 36(3), 238-245, http://dx.doi.org/10.1037/0735-7028.36.3.238.

Chatzichristou Ch., (Ed.) (2011b). Social and Emotional Education: A Program for the Promotion of Mental Health and Learning in the School Community. Educational Material for Teachers and Students II, Community. Athens: Typothito $\Xi \varepsilon v o ́ \gamma \lambda \omega \sigma \sigma \eta$

Cicchetti, D., \& Rogosch, F. A. (1997). The role of self-organization in the promotion ofresilience in maltreated children.Development and Psychopathology,9, 797-815.

Cohen, L. \& Manion, L. (1994). Research methods in education. London and New York: Routledge.

Dimitropoulos, E., G. (2001). Introduction to the Methodology of Scientific Research. Towards a Systemic Dynamic Model of Scientific Research Methodology (3rd ed.), Published by Ellin, Athens.

Fergus, S., \& Zimmerman, M. A. (2005). Adolescent resilience: A framework for understanding healthy development in the face of risk. Annual Review of Public Health, 26, 399-419.

Foti, P. (2020). Separation stress management and smooth transiotion in preschool children and parental counseling- Theory and research in European Journal of Education, Vol 7, No 12, 423-442. doi.org/10.46827/ejes.v7i12.3434

Garmezy, N., \& Masten, A. S. (1991). The protective role of competence indicators in children at risk. In E. M. Cummings, A. L. Greene, \& K. H. Karraker (Eds.), Lifespan developmental psychology: Perspectives on stress and coping (pp. 151-174). Hillsdale, NJ: Erlbaum.

Gutman, L. M., Brown, J., Akerman, R., \& Obolenskaya, P. (2010). Change in wellbeing from childhood to a: risk and resilience. London: Institute of Education.

Koliopanou, A., Syfaki M. (2011). Crisis Management - Dealing with Mourning in the school environment, in The special education is the starting point of developments in science and practice., In The special education is the starting point of developments in science and practice., 2nd Panhellenic Special Conference Agogi, t.DD, Athens: Grigori

Lagoumintzis, G., Vlachopoulos, G., Koutsogiannis, K. (2015). Research Methodology in Health Sciences, SEAB, Athens.

Luthar, S. S., \& Cicchetti, D. (2000). The construct of resilience: Implications for interventions and social policies. Development and Psychopathology, 12, 857-885.

Masten, A. S. (2001). Ordinary magic: Resilience processes in development. American Psychologist, 56(3), 227-238

Ouzouni Ch. \& Nakakis K., (2011). The Reliability and Validity of Measuring Tools in Quantitative Studies, Continuing Education Article, Nursing, 50 (2): 231-239. 
Pappas, Th. (2002). The methodology of scientific research in the humanities. Kardamitsa Publications

Paraskevopoulos I. (1999). Interpersonal and intrapersonal adaptation questionnaire. Greek Letters, Athens.

Miller, D., \& Daniel, B. (2007). Competent to Cope, Worthy of Happiness? How the Duality of Self-Esteem Can Inform a Resilience-Based Classroom Environment. School Psychology International, 28(5), 605-622.

Wolin, S.J. and Wolin, S. (1993). The Resilient Self: How Survivors of Troubled Families Rise Above Adversity, Villard Books. 


\section{Appendix: Elements}

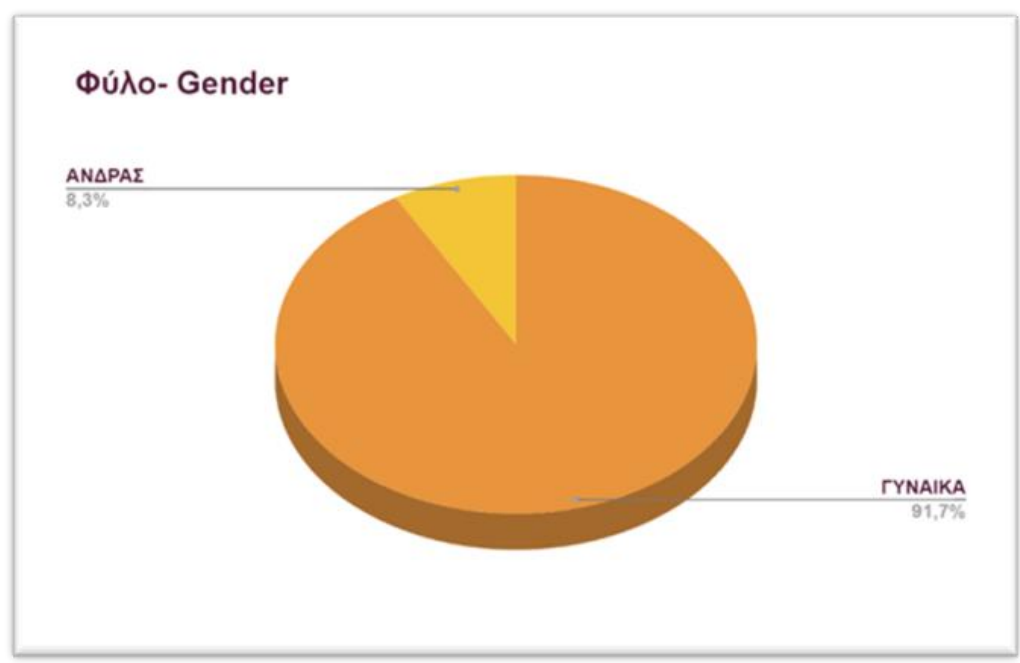

Figure 1: Gender

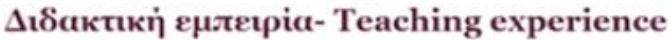

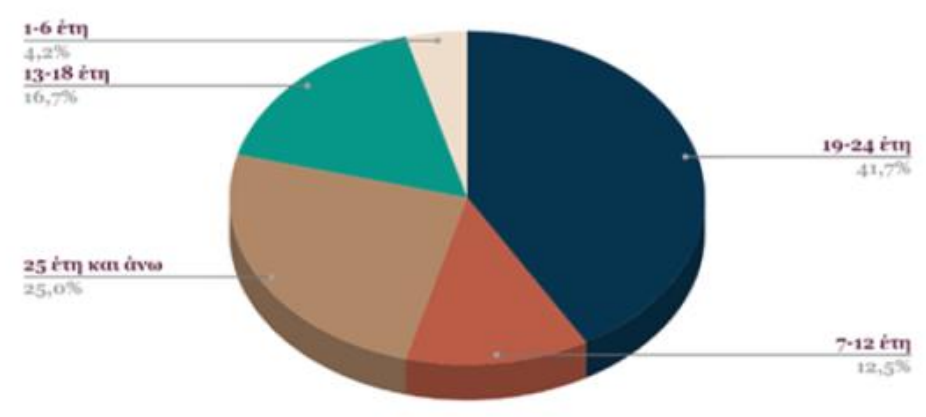

Figure 2: Teaching experience

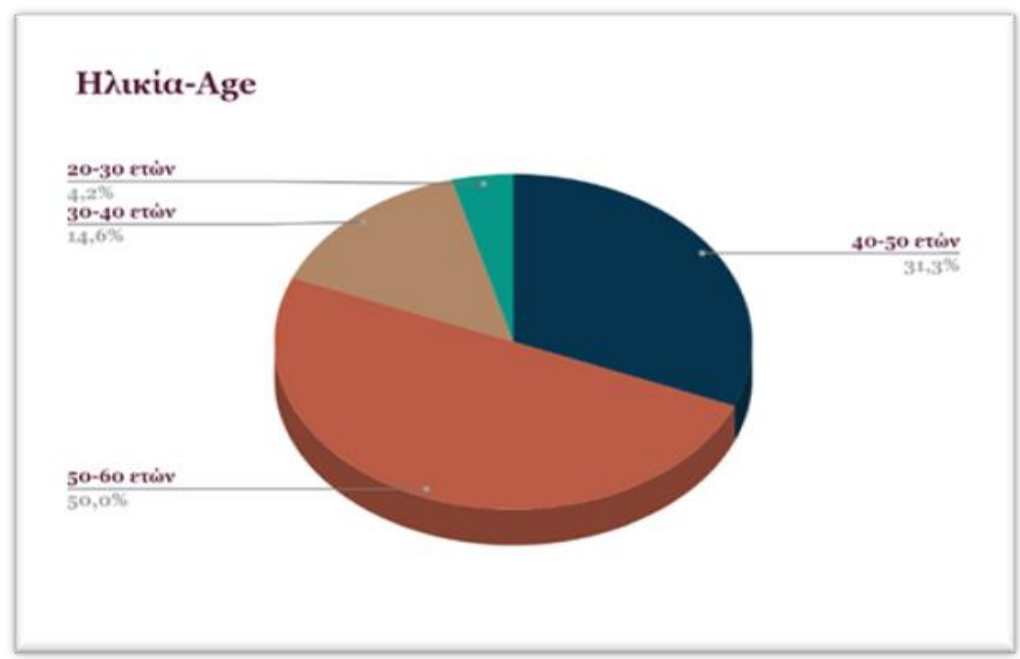

Figure 3: Age 


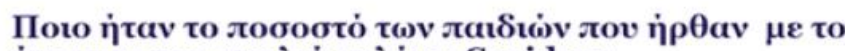
$\dot{a} v o t \gamma \mu \alpha \tau \omega v \sigma \chi 0 \lambda \varepsilon i \omega v \lambda \dot{o} \gamma \omega$ Covid-19;

What was the percentage of children who came to school after the first closure?

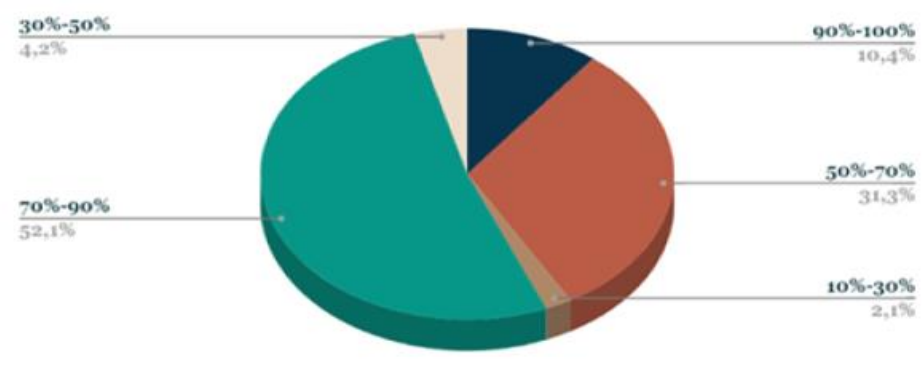

Figure 4: What was the percentage of children who came to school after the first closure due to Covid-19?

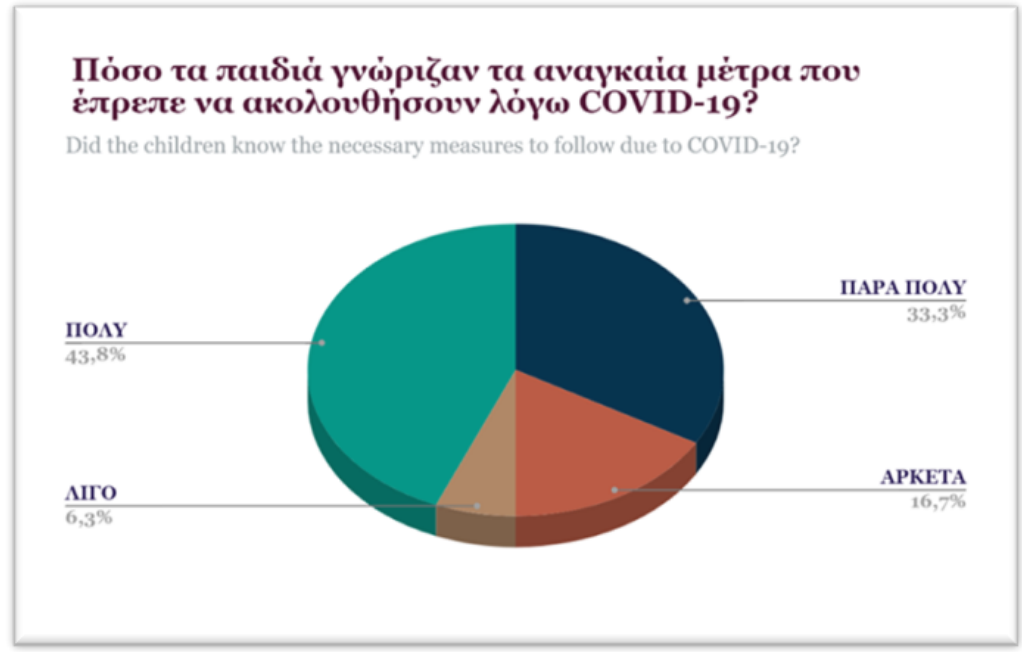

Figure 5: Did children knew about the necessary measurements due to Covid-19?

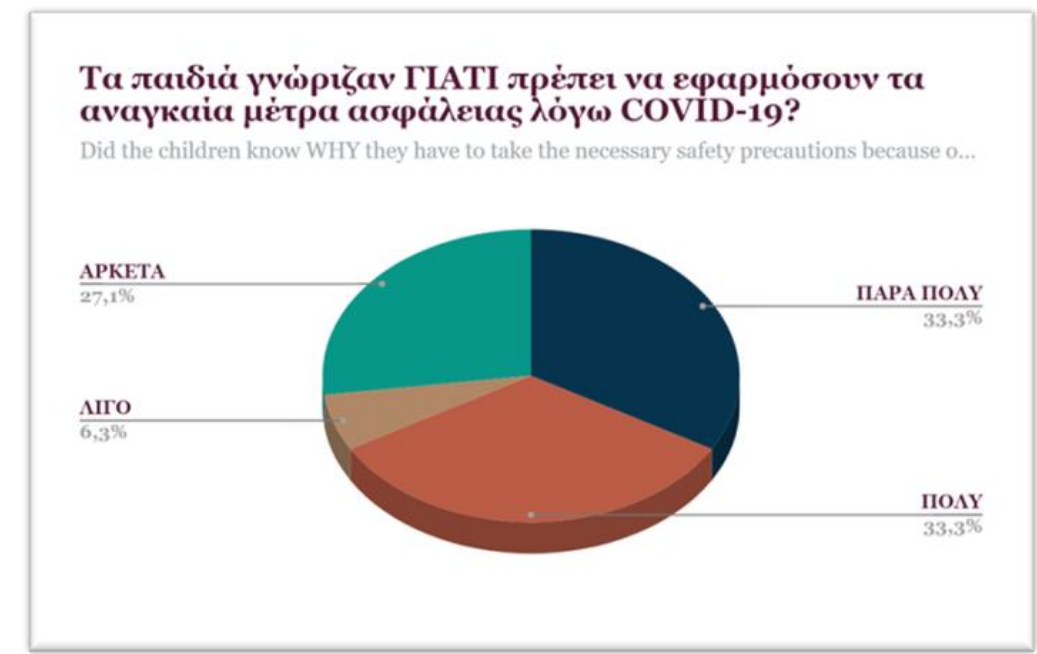

Figure 6: Did the children knew why had to take the necessary safety precautions? 


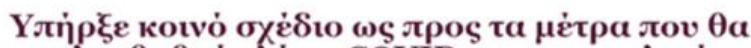

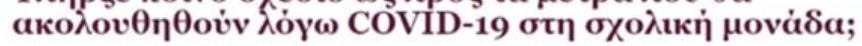

Was there a joint plan for the measures to be followed by the school unit?

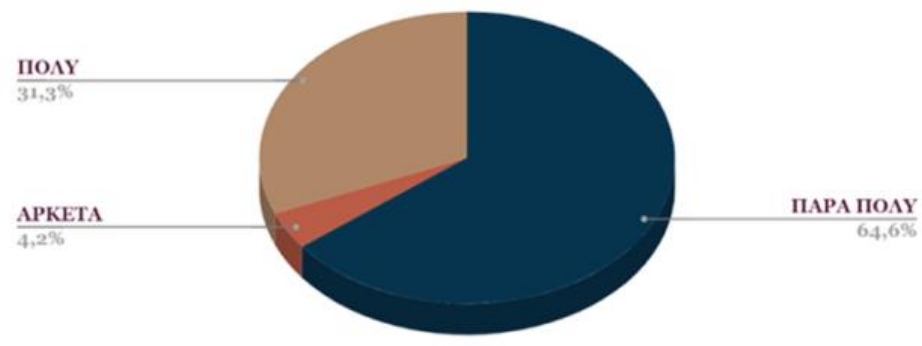

Figure 7: Was there a joint plan for the measurements to be followed by the school unit?

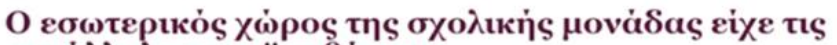

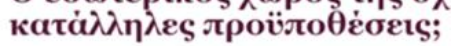

The interior of the school unit had the appropriate conditions according to the protocol?

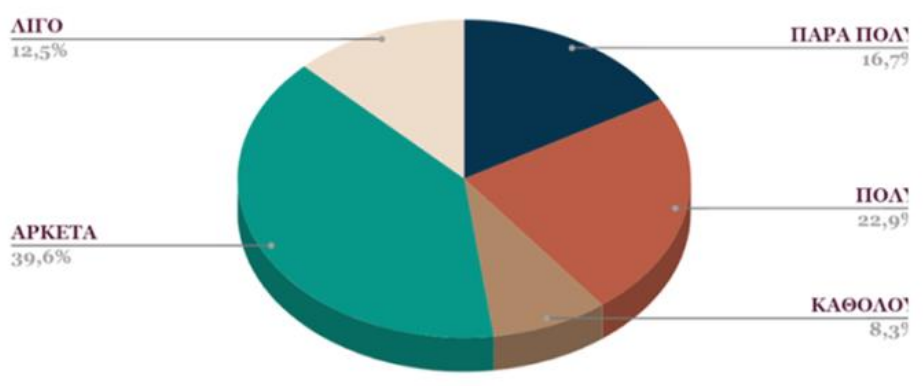

Figure 8: The interior space of the school unit had the appropriate conditions according to the Covid-19 protocol?

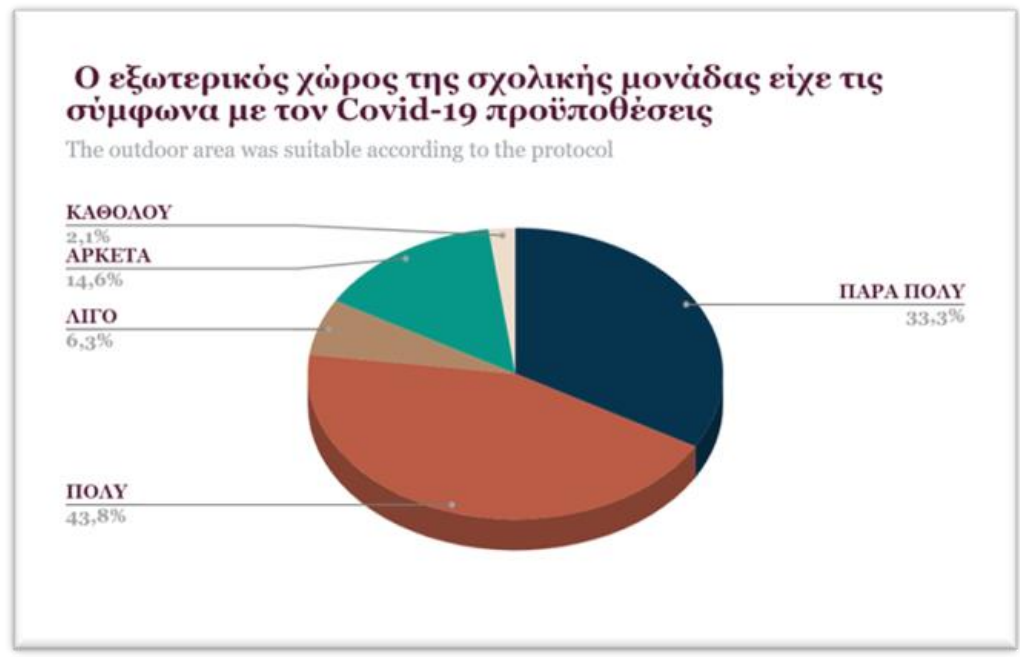

Figure 9: The outdoor are was suitable according to the Covid-19 protocol? 


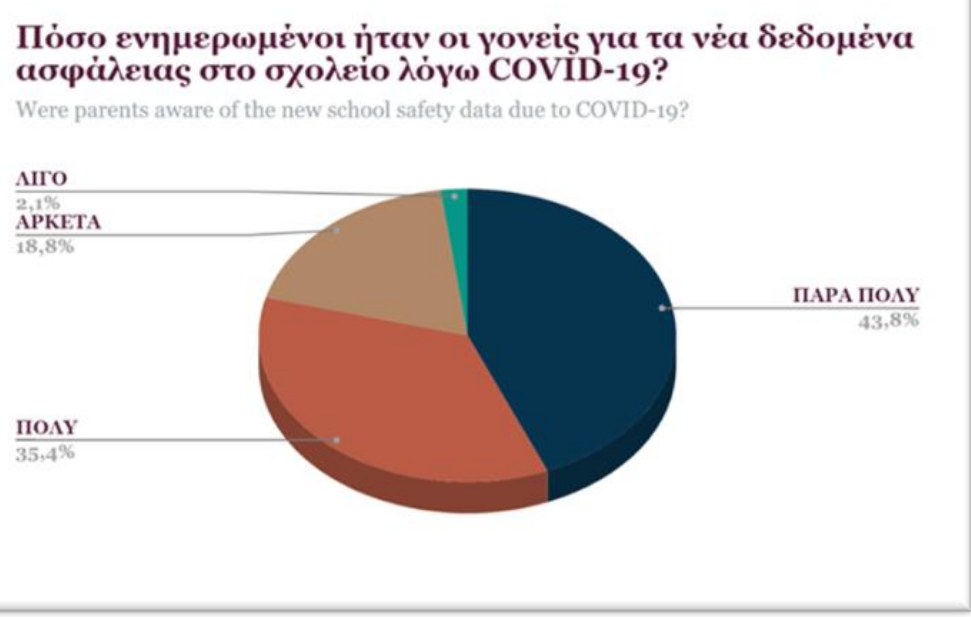

Figure 10: Were parents aware of the new school safety?

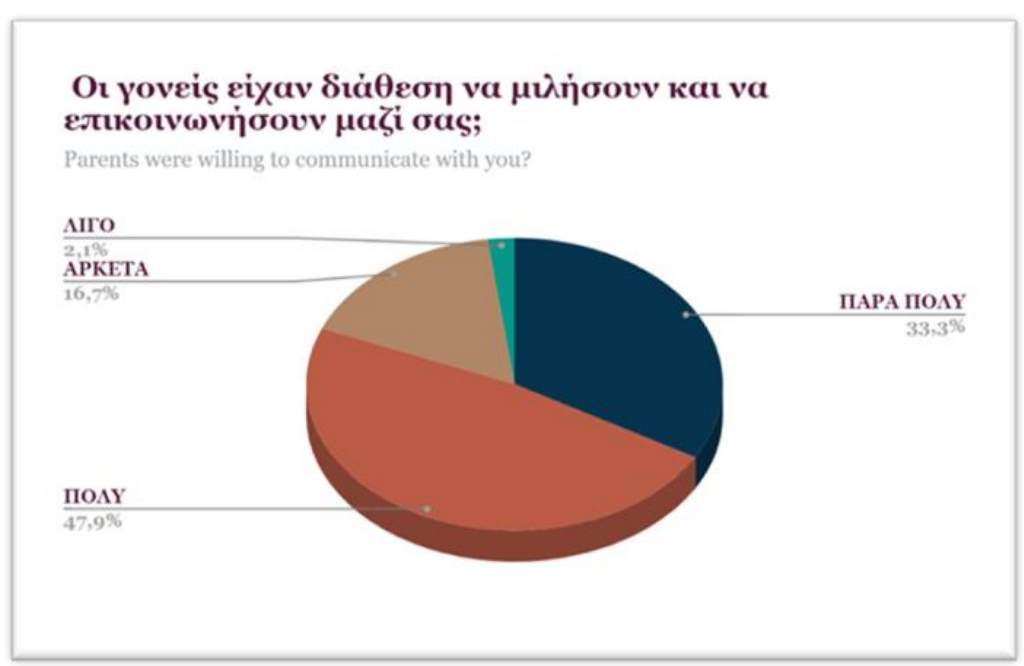

Figure 11: Parents were willing to communicate with you

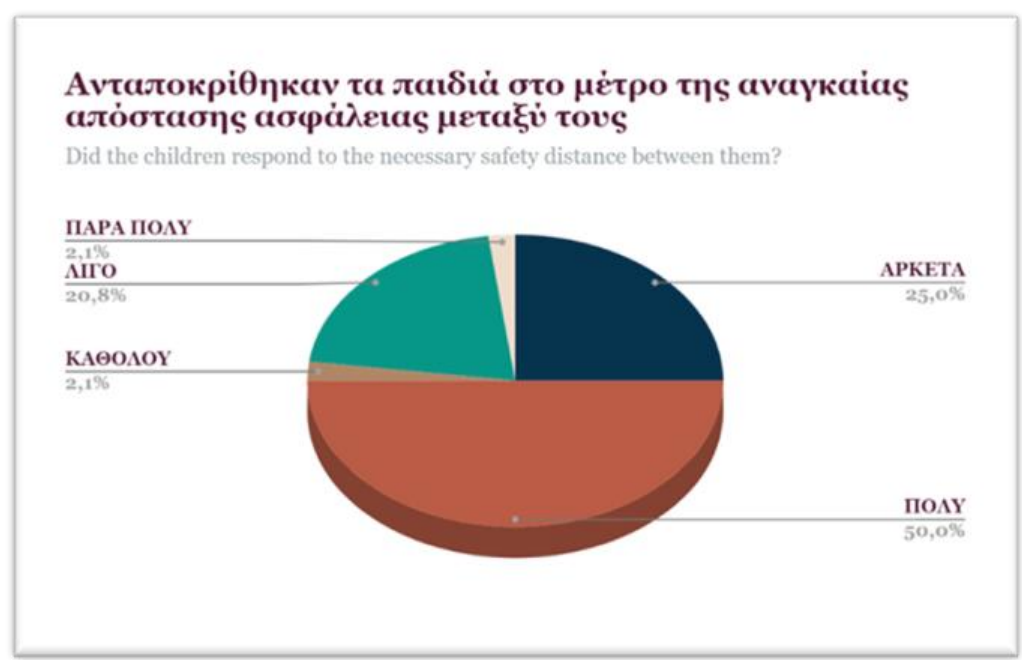

Figure 12: Did the children respond to the necessary safety distance? 


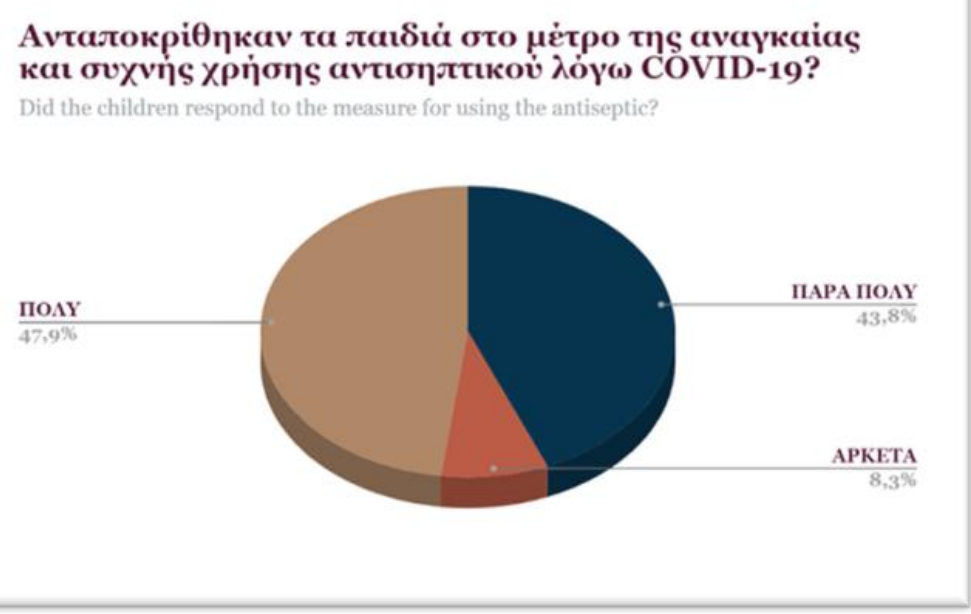

Figure 13: Did the children respond to the often use of antiseptic?

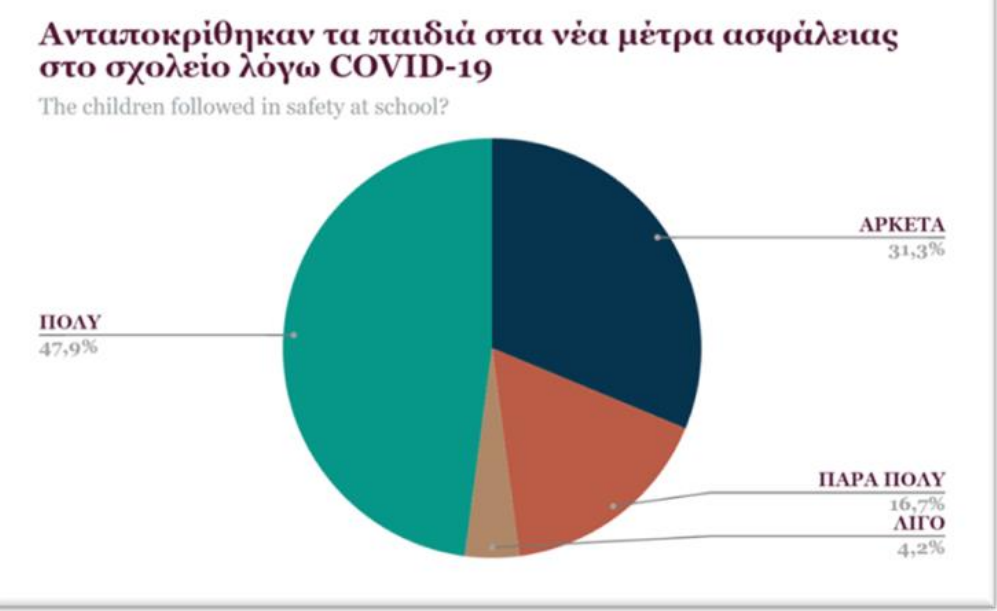

Figure 14: Did children followed the safety measurements at school?

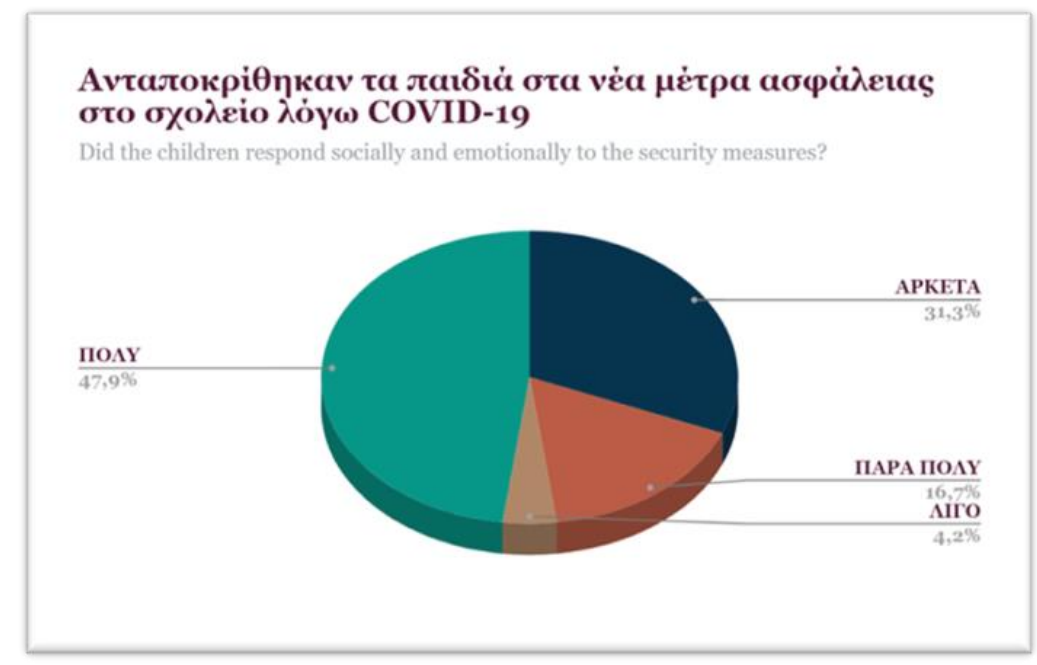

Figure 15: Did children respond socially and emotionally? 


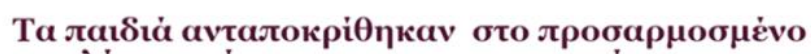

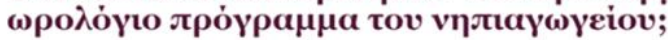

Did the children respond to the new kindergarten schedule?

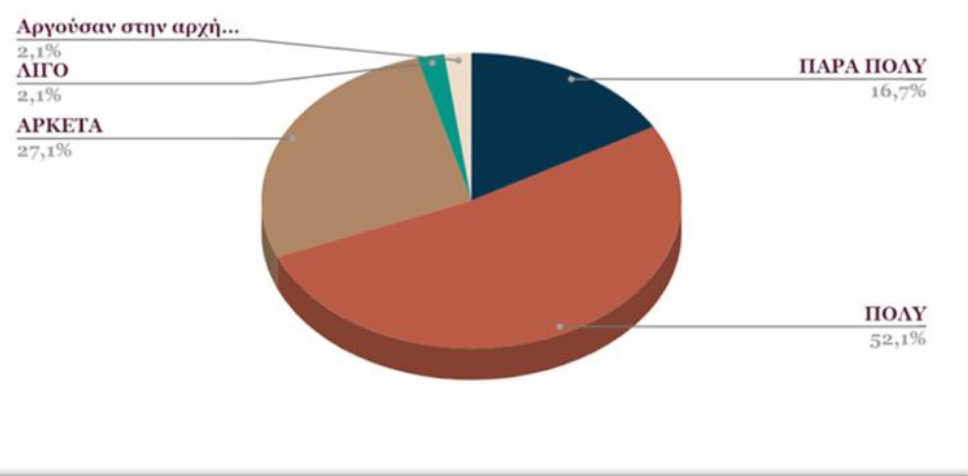

Figure 16: Did children respond to the new kindergarten schedule?

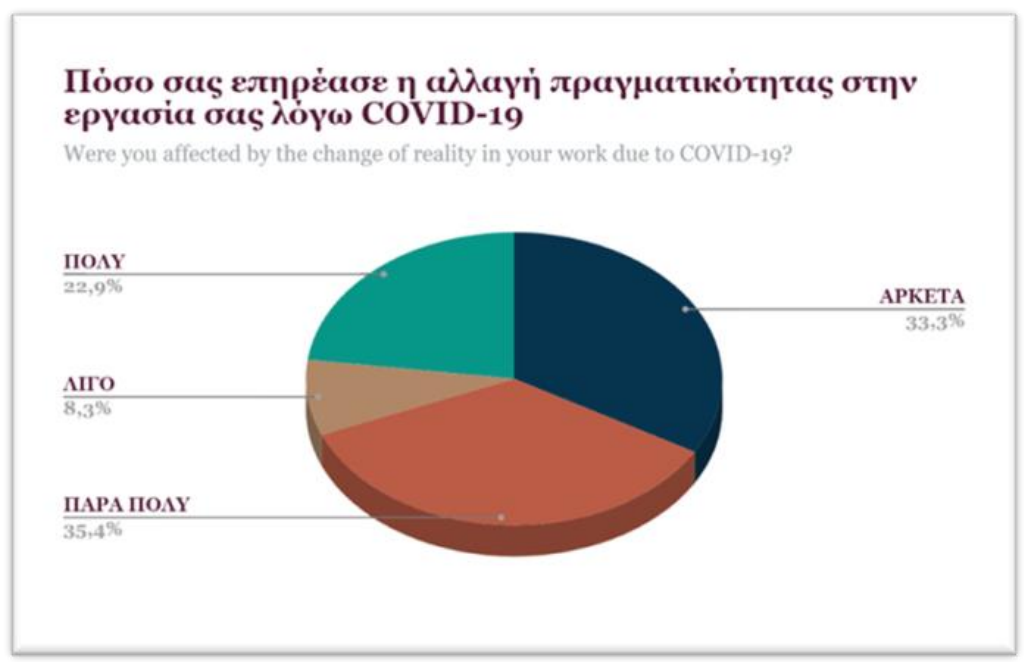

Figure 17: How Covid-19 affected in your reality at school?

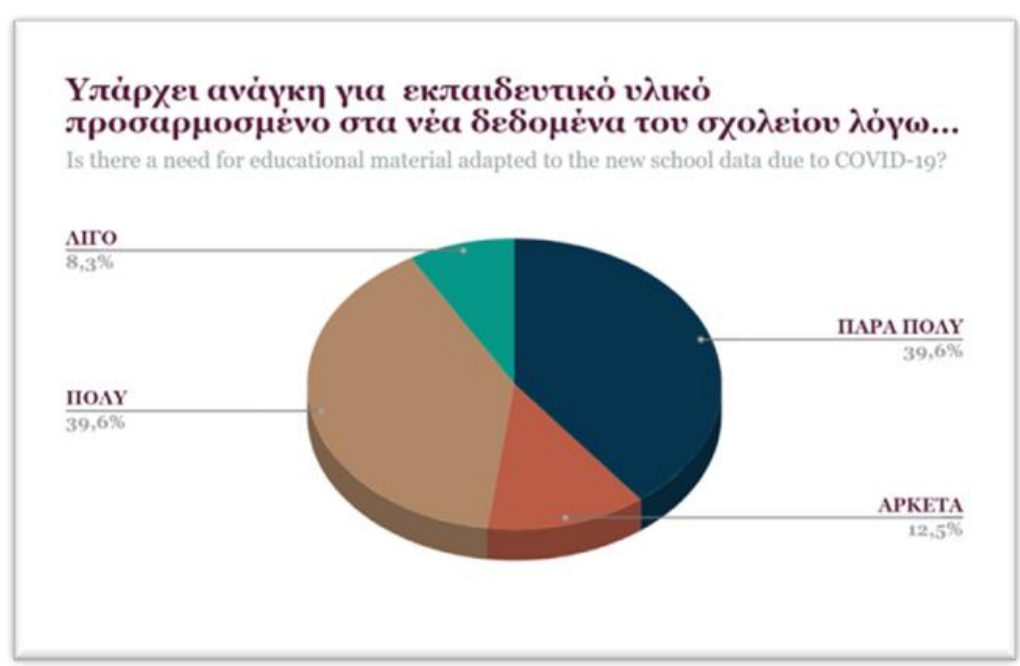

Figure 18: Is there a need for educational material adapted to the new school data? 
Creative Commons licensing terms

Authors will retain the copyright of their published articles agreeing that a Creative Commons Attribution 4.0 International License (CC BY 4.0) terms will be applied to their work. Under the terms of this license, no permission is required from the author(s) or publisher for members of the community to copy, distribute, transmit or adapt the article content, providing a proper, prominent and unambiguous attribution to the authors in a manner that makes clear that the materials are being reused under permission of a Creative Commons License. Views, opinions and conclusions expressed in this research article are views, opinions and conclusions of the author(s). Open Access Publishing Group and European Journal of Open Education and E-learning Studies shall not be responsible or answerable for any loss, damage or liability caused in relation to/arising out of conflict of interests, copyright violations and inappropriate or inaccurate use of any kind content related or integrated on the research work. All the published works are meeting the Open Access Publishing requirements and can be freely accessed, shared, modified, distributed and used in educational, commercial and non-commercial purposes under a Creative Commons Attribution 4.0 International License (CC BY 4.0). 